\title{
AS TRANSFORMAÇÕES TERRITORIAIS E SEUS AGENTES COMO ELEMENTOS GERADORES DE MOBILIDADE POPULACIONAL NO BAIRRO VILA NOVA EM PORTO ALEGRE/RS ${ }^{1,2}$
}

Grupo PET-Geografia ${ }^{3}$

\section{Resumo}

O bairro Vila Nova, localizado em Porto Alegre/RS, vem sofrendo mudanças territoriais nas últimas décadas, tendo o capital, o simbólico e o Estado como agentes sobre esse espaço. Estas mudanças estão associadas a fluxos de mobilidade populacional, havendo diminuição do número de propriedades com atividades agrícolas e o tamanho de suas áreas. O objetivo dessa pesquisa é identificar as transformações territoriais ocorridas no bairro a partir de 1970, analisando o papel destes agentes como geradores de mobilidade populacional. Analisar o reflexo do desenvolvimento da cidade na dinâmica social, política e econômica e o impacto do PDDUA no bairro, identificar o período de instalação das principais infraestruturas nos âmbitos público e privado, mapear as mudanças fundiárias e funcionais ocorridas na área de estudo e as tipologias dos principais fluxos de mobilidades populacionais ocorridas bem como identificar as principais condicionantes da mobilidade de moradores no período ocorridas se fazem necessários. Os procedimentos metodológicos incluem as etapas: interpretação temporal de fotografias aéreas, documentos administrativos da prefeitura e censos demográficos; identificação de antigos agricultores do bairro; aplicação de questionários e entrevistas; identificação e mapeamento de tipologias de mobilidade populacional.

Palavras-Chave: mobilidade espacial, transformações territoriais, identidade.

\section{Introdução}

\footnotetext{
${ }^{1}$ Pesquisa concluída pelo grupo do Programa de Educação Tutorial do curso de Geografia da Universidade Federal do Rio Grande do Sul (PET-GEA/UFRGS).

${ }^{2}$ Artigo Apresentado no XVII SIC/UFRGS, I SINARUB/USP, I ENAPET GEO, II ENGPGEO.

${ }^{3}$ Ana Maria Sanches Dorneles Ferreira de Oliveira; Ana Stumpf Mitchell, Daniel Mallmann Vallerius ; Éverton de Moraes Kozenieski; Felipe Velho Azevedo Costa; Fernando Dreissig de Moraes; Fernando Weiss Xavier; Karen Aline Heberle; Rafael Zilio Fernandes; Renata Ferreira da Silveira; Rodrigo Bennett; Rosa Maria Vieira Medeiros; Stefan Szczesny Rout, Tiago Bassani Rech; Tiago Oliveira Nicoloso.
} 
No decorrer das últimas décadas, a dinâmica dos grandes centros urbanos brasileiros tem seguido às tendências de concentração populacional. Com isso, as estruturas preexistentes nas médias e grandes cidades tiveram que se adaptar a essa tendência forçando um processo de refuncionalização dos espaços públicos e privados; de valorização de áreas outrora desvalorizadas; e de reorganização/reavaliação das infraestruturas disponíveis. Dessa forma, os instrumentos de planejamento e gestão urbanos também tiveram de passar por uma reformulação.

O município de Porto Alegre não é exceção. As transformações territoriais ocorridas no Bairro Vila Nova trazem consigo os impactos da urbanização pela ação de agentes como o poder público, a sociedade civil, iniciativa privada, etc. sobre um espaço historicamente destinado à produção agrícola. Disto surgem contradições, não apenas de uma nova configuração da paisagem e da discussão sobre a tendência de supressão dos espaços rurais nas metrópoles, mas também do modo de vida e das relações sociais, então estabelecidas.

Clarear essas transformações, distinguindo seus agentes condicionantes, torna-se então tarefa necessária para a compreensão das mudanças ocorridas nas últimas décadas dentro das grandes metrópoles brasileiras, enfocando não apenas os aspectos práticos de tais transformações, mas também entender a percepção dos indivíduos envolvidos nesta nova configuração.

O caso do bairro Vila Nova, na Zona Sul da capital gaúcha, exemplifica estes fatos, assim, merecendo uma análise mais detalhada sobre o papel do valor simbólico, do valor de mercado e do poder público como elementos condicionantes de mobilidade populacional associada a um novo padrão de ocupação e uso da terra, a partir de 1970.

Para melhor notarmos a evolução urbana do bairro Vila Nova, buscamos em referenciais históricos do bairro, o primeiro relato da configuração espacial deste. Em seguida, utilizamos e interpretamos temporalmente fotografias aéreas (posteriormente vetorizadas, que resultaram na elaboração de uma figura representativa da utilização do solo) e de documentos administrativos da prefeitura, bem como censos demográficos. Para fins de investigação da atual configuração supracitada, realizamos entrevistas com os expositores da Festa do Pêssego da Vila Nova, também com lideranças do bairro e com as entidades relacionadas ao objeto de estudo. Utilizando o produto da interpretação das fotos aéreas, pontuamos a rua do bairro que consideramos como a mais representativa de mudanças ocorridas e, no percurso da mesma, foram realizadas entrevistas com os moradores do mesmo. 


\section{Porto Alegre e a Vila Nova}

Porto Alegre começou a ser povoada no século XVII e, em 1772, possuía uma população de 1500 habitantes. A partir desse momento, ocorre um aumento de população e conseqüentemente de importância econômica da atual capital do Rio Grande do Sul. Ao longo da evolução - cujos principais agentes transformadores são fatores demográficos, econômicos, socioculturais e locacionais, além da ação do Estado - ocorre uma grande diversificação de funções econômicas e políticas do local. O crescimento, decorrente dos fatores já citados, ocasionou uma inevitável ampliação do centro urbano, ou seja, uma propagação em direção à periferia, já que, preferencialmente essas áreas eram pouco populosas e desvalorizadas em comparação ao centro urbano; fenômeno muito comum, inclusive, em outros países em desenvolvimento.

Segundo De Souza e Müller (1997), a evolução urbana de Porto Alegre pode ser dividida em cinco períodos: o primeiro, comportando o período de 1680 a 1772, corresponde ao início da ocupação do território e a formação do povoado. Concomitantemente, há o surgimento do porto. O segundo $(1772$ - 1820) é marcado pelo aumento da importância do porto devido ao escoamento do trigo plantado pelos colonos. No terceiro (1820 - 1890), ocorre a imigração de colonos alemães e italianos e a afirmação de Porto Alegre na condição de centro comercial, administrativo e militar. O quarto período (1890 - 1945) é caracterizado pelo desenvolvimento industrial, ocasionando o crescimento do comércio. No quinto período (1945 até hoje), observa-se, entre muitos fenômenos, o crescimento da região metropolitana com o aumento de populações de baixa renda residentes em sub-habitações.

A história do bairro Vila Nova, localizado na zona sul de Porto Alegre (Figura 1) começa a partir de um projeto particular de colonização, formada por famílias de imigrantes italianos, chamada inicialmente de Vila Nova D'Itália. As primeiras famílias a se estabeleceram ali foram Passuelo e Dallariva, por volta de 1894, seguidos dos Monteggia, em 1897. A esses moradores seguiram-se outros que foram adquirindo novas glebas de terra. 
Figura 1 - Localização do Bairro Vila Nova e principais ruas
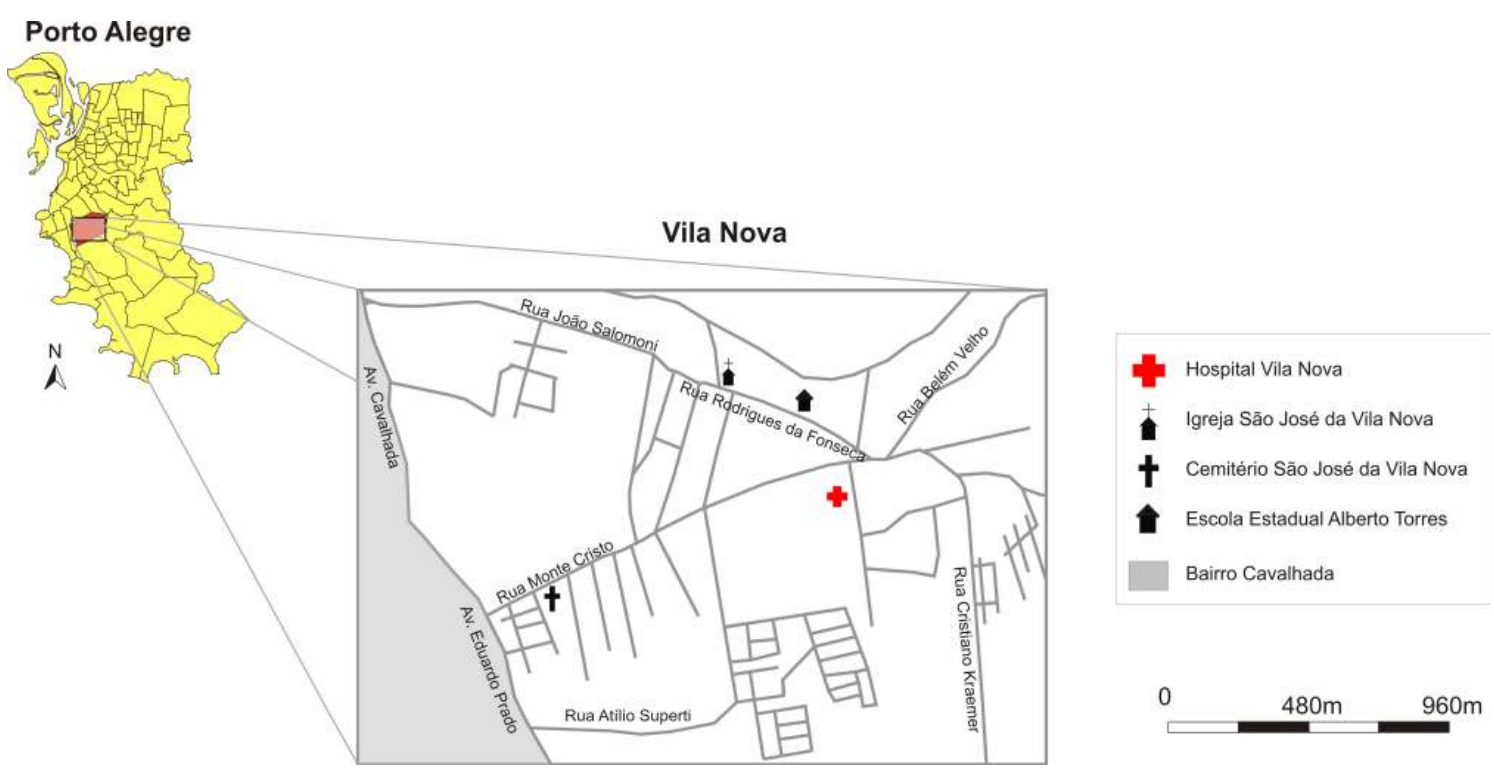

Fonte: PET GEA/UFRGS - Base: fotos aéres METROPLAN (72/91/2002)

As relações entre os moradores da Vila Nova eram típicas de colônias, marcadas por uma rede de reciprocidade. Baseavam-se em reuniões familiares e comemorações religiosas. Aspectos que refletem o bucolismo e o grau de isolamento em relação ao centro de Porto Alegre, nesse momento histórico. A população do bairro era composta por poucas famílias que, com o passar do tempo, dividiram suas terras com seus descendentes.

O bairro se dedicava, basicamente, à plantação de videiras e de árvores frutíferas (pêssegos e ameixas). Sua produção se destinava principalmente ao mercado gaúcho chegando a atingir os mercados de São Paulo e Rio de Janeiro.

As primeiras obras de caráter coletivo do bairro datam de 1897, com a construção da Escola Elementar Villanova ${ }^{4}$, ainda hoje em funcionamento. Podemos destacar também a construção da capela ${ }^{5}$, em 1906, que acabaria por ser o ponto de encontro dos colonos; e a criação da Cooperativa Agrícola em 1911, que tinha como finalidade a venda dos vinhos ali produzidos.

Em 1918 foi realizada pela primeira vez a Festa da Uva de Porto Alegre no bairro Vila Nova, que contou com a presença de autoridades, entre elas, o Real Embaixador D’Itália. A partir de então a festa começou a ser realizada anualmente com a participação de um grande número de moradores de Porto Alegre. Os produtos agrícolas da Vila Nova passam a se destacar na preferência da população porto-alegrense devido a suas qualidades. Entretanto, com a diminuição das áreas destinadas à plantação de uvas e conseqüentemente da produção,

\footnotetext{
${ }^{4}$ Hoje com o nome de Escola Estadual de Ensino Médio Alberto Torres.

${ }^{5}$ Hoje com o nome de Igreja São José da Vila Nova.
} 
essa festa foi substituída pela Festa do Pêssego. A razão desta substituição foi a produção de pêssego ter superado a produção de uvas. A Festa do Pêssego tradicionalmente continua sendo realizada no bairro.

As dificuldades com o transporte dos produtos agrícolas eram um empecilho para o escoamento da produção. Em 1912, o poder público se sensibiliza com as reivindicações dos produtores e cria uma estrada para facilitar o deslocamento desses produtos, ligando a Vila Nova ao bairro Cavalhada. Em 1926, foi inaugurada a linha de ferro que conectava a Vila Nova ao centro da cidade e que foi extinta em 1932. Para que essa obra fosse realizada foi necessário que a Vila Nova passasse a ser uma zona suburbana de Porto Alegre, conforme o PDDUA.

Essa necessidade da melhoria dos meios para o transporte dos produtos agrícola trouxe, como conseqüência, outras inovações. Começam a surgir armazéns, parques, restaurantes - novidades na paisagem do bairro, juntamente com a valorização das propriedades próximas as vias de acesso.

A partir da década de 50, uma nova realidade paira sobre a Vila Nova. Começa a ficar evidente a redução da produção agrícola; o declínio econômico de algumas chácaras; o loteamento de muitas delas; a migração de agricultores; além da chegada de novos moradores com finalidades distintas da agricultura. Em suma, começam a ficar perceptíveis as transformações no bairro, principalmente a perda das características tipicamente coloniais da Vila Nova.

Somando-se a isso, o Plano Diretor de Desenvolvimento Urbano e Ambiental (PDDUA) previa ainda um crescimento dos bairros mais distantes do centro, objetivando descentralizar, principalmente, a função comercial e populacional.

\section{A Influência do Capital nas Dinâmicas Territoriais Encontradas no Bairro Vila Nova - Porto Alegre}

A palavra Valor, é preciso observar, tem dois significados diferentes; algumas vezes expressa a utilidade de algum objeto particular e algumas vezes o poder de compra de outros bens que a posse daquele objeto transmite. O primeiro pode ser chamado 'valor de uso' e o outro, 'valor de troca. (SMITH apud HARVEY, 1980, p.131).

O bairro Vila Nova, conforme apresentado anteriormente, vem mostrando gradativas modificações em sua funcionalidade, finalidade e, conseqüentemente, em sua distribuição 
territorial. Outrora eminentemente agrícola, hoje torna-se refúgio de famílias que, devido a algum motivo, acabam por fazer a opção de estabelecer morada no referido bairro. A ação da iniciativa privada é uma das responsáveis por fomentar tal mobilidade.

Segundo SMITH, a área de estudo em questão acabou tornando-se objeto de cobiça por parte de moradores de outras localidades e, por conseguinte, agregando valor á mesma, possivelmente devido a sua localização, seu potencial de crescimento, e a ação do Plano Diretor municipal, conforme Roberto Lobato Corrêa (1995):

A propriedade fundiária da Periferia Urbana, sobretudo aquela da grande cidade, constitui-se no alvo de atenção dos proprietários de terras. Isto se deve ao fato de estar ela diretamente submetida ao processo de transformação do espaço rural em urbano. As possibilidades dessa transformação são, entretanto, dependentes de um confronto entre as rendas a serem obtidas com a produção agrícola e com a venda de terras para fins urbanos. Mais cedo ou mais tarde, graças ao diferencial da renda, o uso agrícola da periferia é substituído por um urbano, passando, em muitos casos, por uma etapa de esterilização da terra. Há então, um processo de valorização fundiária. $(1995$, p. 56)

Diretamente ligada ao processo de transformação verificado no bairro que, até alguns anos atrás era classificado como área rural, a força do Capital avança sobre um território ainda então pouco visado pelos empreendedores imobiliários, redefinindo as fronteiras urbanas da cidade. Partindo para uma análise histórica, podemos aferir uma significativa queda na área cultivada da Vila Nova, ao mesmo tempo em que o bairro ganha contornos residenciais. As terras lá localizadas, antes concentradas na mão de poucos proprietários, hoje encontram-se repartidas (e porque não dizer, "pulverizadas"). Inicia-se, a partir deste "fatiamento", uma situação onde, segundo nossa percepção, os novos proprietários aplicam seus capitais visando a utilização imediata do imóvel adquirido, e não apenas, como uma simples reserva de mercado.

O presente quadro reflete o processo de descentralização recorrente no município de Porto Alegre, tal como verificado em grande parte das metrópoles brasileiras. Cabe ressaltar, contudo, que esta descentralização apresenta majoritariamente espacial do que financeiro, embora a centralização do capital, ainda que implicitamente seja um dos responsáveis pela referida desnucleação populacional.

\section{O Papel do Poder Público}

Estudar o papel do poder público, em determinado território é estudar como esta esfera do poder atua através da legislação sobre determinada sociedade e quais as ferramentas que 
são utilizadas para tanto, pois estamos diante da produção do espaço pela sociedade e é sob a égide do poder público onde esta produção ganha um caráter estratégico.

Segundo SAMSON apud Corrêa (1989), o Estado possui uma série de instrumentos de organização espacial:

a. O direito a desapropriação precedência na compra de terras;

b. Regulamentação do uso do solo;

c. Controle e limitação dos preços de terras (terrenos, lotes);

d. Limitação da superfície da terra de que cada um pode se apropriar;

e. Impostos fundiários e imobiliários que podem variar segundo a dimensão do imóvel, uso da terra e localização;

f. Taxação de terrenos livres;

g. Mobilização de reservas fundiárias públicas, afetando o preço da terra e orientando espacialmente a ocupação do espaço;

h. Investimento público na produção do espaço, através de obras de drenagem, desmontes, aterros e implantação da infra-estrutura;

i. Organização de mecanismos de credito a habitação;

j. Pesquisas, operações-teste sobre materiais e procedimentos de construção, bem como o controle de produção e do mercado deste material.

Nesse sentido, falar sobre o bairro Vila Nova implica, antes de mais nada, buscar os mecanismos de legitimação de mudanças espaciais no PDDUA, pelo fato do mesmo ser a principal ferramenta de planejamento participativo da cidade.

Como agente condicionante de transformações sócio-espacias, o PDDUA tem a tarefa, nesse caso, de descentralizar as funções que outrora pertenciam ao centro de Porto Alegre, bem como organizar e planejar a sua dinâmica. Assim, o poder público atua na implementação de infra-estruturas púbicas, de acordo com os interesses tanto da sociedade como das empresas em geral.

$\mathrm{Na}$ cidade de Porto Alegre, o bairro Vila Nova foi atingido pelas políticas públicas adotadas, tanto no que se refere à questão tributaria, através da substituição do Imposto Territorial Rural (ITR) pelo IPTU, como pela nova organização de um espaço que anteriormente era, predominantemente, de identidade rural. Dessa forma, seguindo a tendência atual das metrópoles de descentralizar e redistribuir as áreas residenciais, na forma de condomínios de luxo, de reassentamentos urbanos ou ainda pela disposição de infra- 
estruturas, ocorreu, no caso da Vila Nova, a substituição de uma área historicamente voltada à produção agrícola por uma área predominantemente residencial.

Segundo Cléia Beatriz Hauschild de Oliveira, arquiteta e Coordenadora de Estudos Urbanos da Secretaria do Planejamento Municipal:

(...) o novo Plano Diretor, constituído por sete estratégias, destaca dentre elas as de 'Qualificação do Patrimônio Natural' e a de 'Promoção Econômica e Geração de Postos de Trabalho', as quais ao disciplinar e ordenar a ocupação do solo urbano associa conceitos básicos à idéia de, entre outras, garantir a manutenção e proteção do patrimônio natural; promover as condições de saneamento completo; revalorizar o papel de Porto Alegre como pólo econômico e metropolitano e promover o valor agregado à produção rural. Na estratégia do Uso do Solo Privado é proposta a extensão do conceito de urbano para a zona rural resguardando as áreas de produção primária e incentivando tecnologias próprias para o desenvolvimento da agroecologia, diversamente do que ocorre nas zonas rurais de outras regiões do Estado (do RS), (OLIVEIRA, 1997, p. 87) ${ }^{6}$

Cabe ressaltar que o valor agregado está na utilização da agroecologia com cunho turístico, projeto já existente e implementado como "Turismo Rural" em Porto Alegre pela Prefeitura Municipal, com o apoio técnico do Centro de Desenvolvimento Agrícola (CAD), um órgão da Prefeitura. Neste caso, fica evidente a transformação de um ambiente de função que antes era rural em uma mercadoria, de forma bastante explícita. De acordo com Antônio Bertacco, que tem uma propriedade que está cadastrada nos roteiros turísticos rurais, também chefe do $\mathrm{CAD}$ e pequeno produtor do bairro, o referido órgão público é um dos principais fomentadores desta nova modalidade de turismo junto aos pequenos produtores da Vila Nova.

A efetivação de Porto Alegre como cidade completamente urbanizada altera, como vimos anteriormente, diretamente o montante da arrecadação do município sem que, em momento algum o PDDUA mencione a distribuição de tais arrecadações.

Todavia, por meio de mecanismos de pressão da comunidade do bairro Vila Nova, a alíquota da arrecadação foi alterada para algumas exceções. Com a mudança do PDDUA, o bairro passa a ser taxado com tarifação residencial na íntegra. As exceções se dão para os casos de produtores rurais que, mediante certificação reconhecida do exercício de atividades agrícolas, passam a obter isenção ou a redução da alíquota, baseada na tarifa do ITR.

De acordo com o estudo denominado "Caracterização e tendências da rede urbana do Brasil”, uma parceria do Instituto de Pesquisas Econômicas Aplicadas (Ipea), do IBGE e do Núcleo de Economia Social, Urbana e Regional da Unicamp, em 1999, a taxa de urbanização brasileira era de $60 \%$. Segundo o Censo de 2000, a taxa de urbanização de Porto Alegre é de

\footnotetext{
${ }^{6}$ Grifos e parênteses nossos.
} 
$81,23 \%$. Todavia, os municípios possuem autonomia para definirem suas taxas de urbanização. Este fato pode acarretar em uma diferença quanto aos dados estatísticos que representam tal situação. Isso reflete, na verdade, a intenção das prefeituras de ampliar suas fontes de arrecadação e, conseqüentemente, de diferenciação espacial.

O espaço, de acordo com Milton Santos, “é um conjunto indissociável de sistemas de ações e de sistemas de objetos" (2004, p.63), ou seja, tudo está contido nele, portanto, pode-se dizer que o urbano é fruto das relações sociais, e isso implica também na relação do poder publico com políticas de pretensas intenções de controle do espaço em seus usos e ocupações.

Segundo Roberto Lobato Correa:

Esta complexa e variada gama de possibilidades de ação do Estado capitalista não se efetiva ao acaso. Nem se processa de modo socialmente neutro, como se o Estado fosse uma instituição que governasse de acordo com uma racionalidade fundamentada nos princípios de equilíbrio social, econômico e espacial, pairando acima das classificações sociais e de seus conflitos. $(1989$, p. 62)

Segundo Ana Fani Alessandri Carlos:

A Questão a partir da produção do espaço é como se ampliam e aprofundam, no mundo moderno, as contradições decorrentes da reprodução da sociedade num momento de generalização da urbanização anunciada pelo desenvolvimento da cidade , isto é com sua "explosão". Assim se revelaria um debate profícuo aquele das relações entre o Estado e o espaço através, por exemplo, das políticas públicas. $(2003,89)$

O Plano Diretor serve como importante instrumento para que o estado discuta com a sociedade a melhor orientação do desenvolvimento da cidade, de acordo com os interesses da população, respeitando suas múltiplas manifestações culturas, tradições, história e identidade.

\section{A Influência do Caráter Simbólico}

Através de entrevistas realizadas com agricultores e moradores do bairro Vila Nova, buscamos verificar como a expansão urbana de Porto Alegre trouxe mudanças nas características desse bairro. Procuramos verificar como o encontro de elementos urbanos com outros rurais atuam na identidade daqueles que ali habitam.

Nesta ocasião, seis foram aplicadas com agricultores durante a realização da $21^{\text {a }}$ Festa do Pêssego. Neste tradicional evento do bairro, os produtores e suas frutas são o centro das atenções, e há a interação entre os próprios agricultores, e destes com os demais moradores do local. Este é o principal evento no qual os agricultores expõem seus cultivos, com atenção 
especial ao pêssego. De acordo com Carneiro (2004), a Festa do Pêssego é um desses momentos em que se pode encontrar a "manifestação de práticas culturais entendidas como "rurais" em espaços definidos como "urbanos"(...)" .

Os agricultores e seus familiares, através de um contato direto com o público, compartilham um momento onde se deixam perceber como tais. Através do diálogos com os expositores, fica nítida a alegria deles ao perceberem que além de seus produtos, eles mesmos são valorizados. De acordo com os expositores, “A Festa está muito bem organizada, só deveria ser mais divulgada. Quando a gente vem aqui vender as frutas, dá alegria porque o nosso trabalho é reconhecido".

Durante o trabalho de campo, observou-se que hoje os moradores do bairro percebem o local como detentor de um número maior de aparelhos urbanos, mas conservam, em suas memórias, lembranças de um lugar tipicamente rural, ao fazerem referência às plantações e à antiga predominância de agricultores em relação aos outros moradores. Ao ser questionado sobre as mudanças ocorridas no bairro, um dos moradores assim respondeu:

Muita mudança, agora tem morador novo, muita gente, e com isso também tem ônibus, farmácia. Antes tudo era plantação de pêssego, figueira, agora tem menos agricultor, mas ainda tem. (morador, 64 anos, há 23 anos residente no bairro).

Pelo depoimento anterior é possível perceber como a paisagem do bairro, outrora rica em elementos agrários, é compreendida dentro de uma situação de contraposição ao avanço de características relacionadas ao fenômeno denominado urbanização, como a densa habitação, a proximidade dos meios de transporte e ao comércio. Este processo também é perceptível através da constatação da diminuição do número de chácaras, causada pelo incentivo do poder público aos investimentos imobiliários tanto da iniciativa privada quanto da própria prefeitura. "A urbanização está apertando cada vez mais os agricultores, devido à especulação imobiliária”. (agricultor, 47 anos no bairro).

Além do setor imobiliário é interessante notar que a chegada das vilas78 também seria um fator de mobilidade de muitos agricultores do bairro. As transformações provocadas pela expansão urbana no bairro Vila Nova trouxe também novos loteamentos e os moradores dessas, parecem figurar como "vizinhos indesejáveis". "Botaram muita vila aí, daí esses marginais roubam tudo, invadem os terrenos. "Não adianta botar grade, eles entram e não tão nem aí. Porque plantar pra levarem?” (agricultor, 49 anos, há 13 anos residente do bairro).

\footnotetext{
${ }^{7}$ São loteamentos habitados por famílias de baixa renda, inseridas no local mais recentemente.
} 
Quando perguntamos aos produtores porque se consideravam agricultores, alguns deles adotaram um discurso carregado de valores sentimentais, no qual a terra seria um patrimônio da família e a prática da agricultura seria algo de tradição.

Eu sou advogado e pratico a agricultura, pois é ela que me garante o sustento durante as férias. Aqui em Porto Alegre não dá pra viver só do plantio. Sou produtor de $5^{\mathrm{a}}$ geração, com muito orgulho, e a agricultura é algo que aprendi com o meu pai, sempre o acompanhei e segui no ramo. (agricultor, 45 anos no bairro).

Entretanto, esses mesmos agricultores que consolidam sua própria identidade por discursos saudosistas e pela distinção entre eles e os moradores das vilas, quando indagados sobre se incentivariam seus filhos a seguirem na agricultura, a maior parte dos depoimentos apresenta diferentes manifestações de descontentamento com a agricultura e as dificuldades resultantes dessa. "Ah, os guris não querem trabalhar aqui, tão tudo estudando, um estuda veterinária e o menor, tá no colégio também vai pra fora. (...) Mas a terra vai ficar pra eles (...).” (agricultor, 48 anos, há 20 anos residente do bairro). “(...) Acho que a agricultura já não vai servir pro sustento deles, é uma vida sofrida e que não traz muito dinheiro.” (agricultor, 47 anos no bairro).

Pode-se observar que há indícios da busca, por parte dos agricultores e pelos seus fillhos, de meios de vida cada vez mais semelhantes ao dos demais moradores da Vila Nova, deixando um sentimento de que, cedo ou tarde, a agricultura perderá espaço em prol do avanço das áreas urbanas, dando continuidade ao processo de transição vivenciado no referido bairro.

\section{Análise Temporal Das Fotografias Aéreas}

A análise das fotografias aéreas dos anos 1972, 1991 e 2002 permitiu verificar as transformações no uso da terra no bairro, destacando uma significativa redução da área agrícola e uma expansão da área residencial.

Figura 2 - Mudanças no uso do solo 

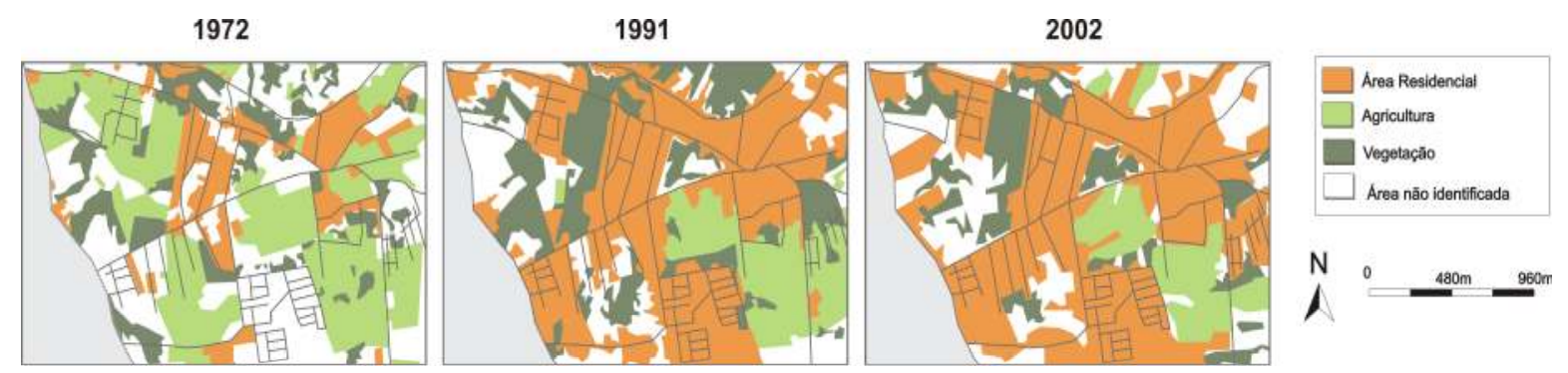

Fonte: PET GEA/UFRGS - Base: fotos aéreas METROPLAN (72/91/2002)

Ainda podemos observar na imagem de 1972 a presença das principais características que originalmente compunham a paisagem do bairro decorrentes do predomínio da agricultura. A partir de então, as mudanças foram acontecendo e as áreas residenciais passaram a predominar em relação às áreas agrícolas. É um processo de reconfiguração da paisagem que, no entanto, ainda mantém algumas das características originais que até hoje são referências para a comunidade, tais como os produtos agrícolas e os cenários bucólicos do bairro.

As alterações das características do bairro, conforme as primeiras entrevistas, provocaram uma progressiva mudança no perfil dos moradores, bem como, nos seus hábitos e nos seus costumes.

Apesar de ter havido uma redução na área agrícola, ainda há remanescentes da mesma. Na figura 2, a ocupação referente ao ano de 1991 mostra que houve uma intensa ocupação de áreas outrora cultivadas, nos remetendo a uma tendência de crescente substituição dos espaços rurais para os próximos anos. Todavia o recorte entre o período de 1991-2002 indica uma relativa estagnação dessa dinâmica, observada através das fotos onde é identificada a permanência de áreas agrícolas em contraposição à tendência presente de urbanização.

Nos pontos onde se identificou visualmente a manutenção de atividades agrícolas, foram feitas as entrevistas de caráter qualitativo, que permitiram a qualificação do presente trabalho.

\section{Considerações Finais}

As alterações sócio-espaciais ocorridas no bairro ao longo das décadas estudadas podem ser observadas através do papel primordial da iniciativa privada como agente modificador do mesmo. Porto Alegre, não fugindo à tendência brasileira, tende à expansão da mancha urbana, onde a maior parte da população vive nos grandes centros urbanos. Tal fato é expresso no bairro pela utilização de áreas outrora destinadas a práticas agrícolas e agora 
utilizadas para fins residenciais ou comerciais, através, principalmente, das dinâmicas econômicas.

O Estado atua de forma a legitimar as necessidades sociais, atendendo ou não os diversos interesses de diferentes grupos, utilizando-se do seu instrumento legal mais efetivo, o Plano Diretor de Desenvolvimento Urbano e Ambiental.

O caráter simbólico pôde ser percebido através das vivências e entrevistas realizadas com os agricultores e moradores do bairro, percebendo-se que os mesmos estão vivendo um momento de transição. Este se situa entre o período que historicamente o PDDUA definia o lugar como "rural" para o período atual no qual o bairro é classificado como "urbano". Apesar disso a presença dos agricultores, acrescida da realização da Festa do Pêssego, retoma toda a memória deste passado, que denotava um ambiente agrícola. É neste contexto que os agricultores e moradores são forçados à identidade, cada vez mais envolvidos e sufocados, simbólica e fisicamente envolvido pela nova situação.

\section{Referências Bibliográficas}

BOMBARDI, Larissa Mie. O bairro rural como identidade terrirotial: a especificidade da abordagem do campesinato na geografia. Revista Agrária, São Paulo, p.55-95, 2004.

CASTELlS, Manuel. O Poder da identidade. $3^{\mathrm{a}}$ ed. São Paulo: Paz e Terra, 2001. 530p

CARLOS, Ana Fani Alessandri, resenha da obra, José Eli da Veiga. Cidades Imaginárias: o Brasil é menos urbano do que se calcula. Campinas- São Paulo, Editores Associados, 2002. Apresentada na Revista Geousp 13 (2003).

CORREA, Roberto Lobato. O espaço urbano. Ática, São Paulo, 1989.

FRANCO, Sérgio da Costa. Porto Alegre: guia histórico. $2^{\mathrm{a}}$ ed. Porto Alegre: Ed. Da Universidade/UFRGS, 1992. P. 431-432.

HALL, Stuart. A identidade cultural na pós-modernidade. 10. ed. Rio de Janeiro: DP\&A, 2005. 102 p.

MALLMANN, Ana Maria Monteggia. Vila Nova: Depoimentos. Porto Alegre: SMIC, 1991.

MENEGAT, Rualdo e outros. Atlas ambiental de Porto Alegre. 2. ed. Porto Alegre: Editora da Universidade/UFRGS, 1999., 228 p

MEDEIROS, Rosa Maria Vieira. Camponeses, cultura e inovações. Campo - Território : Revista De Geografia Agrária, Uberlândia, n. , p.41-59, fev. 2006. 
OLIVEIRA, Cléia Beatriz Hauschild de. PDDUA, in: PORTO ALEGRE, Prefeitura Municipal de. PDDUA, Porto Algre: SMP, 1997.

RAFFESTIN, Claude. Por uma geografia do poder. São Paulo: Ática, 1993. 270p.

RUA, João. Urbanidades no Rural: o devir de novas territorialidades. Campo - Território : Revista De Geografia Agrária, Uberlândia, n. , p.82-106, fev. 2006.

SANTOS, Milton. Espaço e Método. São Paulo: Nobel, 1985. 88 p.

SANTOS, Milton. A natureza do Espaço: tempo e espaço, razão e emoção. Edusp, São Paulo: 2004

SCHNÄNDELBACH, Carla Volanova. A noção da ruralidade e a construção identitária de agricultores em um meio citadino: o caso da Vila Nova e arredores - Porto Alegre/RS. 2004. 134 f. Dissertação (Mestrado) - Curso de Faculdade de Ciências Econômicas, Departamento de PGDR, Universidade Federal do Rio Grande do Sul, Porto Alegre, 2004.

SOUZA, Célia Ferraz de; MÜLlER, Dóris Maria. Porto Alegre e sua Evolução Urbana. Porto Alegre: Ed. Universidade/UFRGS, 1997. 127p. 